Synthesis, vol. 25 nº 1, e031, junio 2018. ISSN 1851-779X

Universidad Nacional de La Plata.

Facultad de Humanidades y Ciencias de la Educación.

Synthesis

Centro de Estudios Helénicos

\title{
La cosmología y sus elementos en Prometeo encadenado
}

\author{
David García Pérez * \\ * Universidad Nacional Autónoma de México, México
}

Cita sugerida: García Pérez, D. (2018). La cosmología y sus elementos en Prometeo encadenado. Synthesis, 25(1), e031. https://doi.org/10.24215/1851779Xe031 


\section{La cosmología y sus elementos en Prometeo encadenado \\ Cosmology and its Elements in Prometheus bound}

\section{David García Pérez*}

Universidad Nacional Autónoma de México, México

\section{Resumen:}

En este artículo se exploran algunos postulados del pensamiento presocrático presentes en la obra de Esquilo, en especial los referentes a la cosmología y a los elementos que se encuentran en esta. Se propone que la tragedia esquilea, en particular Prometeo encadenado, es un nexo entre el pensamiento presocrático y algunas conjeturas políticas y filosóficas del siglo V, si se acepta que tal pieza trágica es de este autor (cf. Solmsen, 1995: X; Saïd, 1985: 9-12; Conacher, 1980: 141-174), de manera que el drama se manifiesta como un espacio en el que la confrontación de dos modos de pensar la cosmología da como resultado una original comprensión de lo trágico y del devenir del cosmos. ${ }^{1}$

Palabras clave: Esquilo, Cosmología, Elementos, Pensamiento presocrático, Prometeo.

\section{Abstract:}

This article explores some ideas of pre-socratic thought present in Aeschylus' plays, especially those concerning cosmology and its elements. The idea of the Aeschylus dramaturgy, in particular Prometheus vinctus, as a nexus between both pre-Socratic and the political and philosophical thought at the Fifth Century, is developed in this article. If we accept that this tragedy was written by Aeschylus (cf. Solmsen, 1995: X; Said, 1985: 9-12; Conacher, 1980: 141-174), so that the drama is manifested as a space in which the confrontation of two modes of thinking cosmology results in an original understanding of the tragic and the becoming of the cosmos.

KEYWORDS: Aeschylus, Cosmology, Elements, Pre-socratic thought, Prometheus .

Los mitos de origen que expresan los componentes de la cosmología suponen un antes que requiere ser explicado para entender el presente en el que se cuentan. Los relatos cosmológicos se prolongan en los mitos de origen, pero estos aportan la argumentación de los cambios operados en el tránsito entre unos y otros, tomando siempre en cuenta los componentes que pretenden explicar el origen mismo de todas las cosas. ${ }^{2}$ Esto es, a cada metamorfosis que se opera en el cosmos primigenio, corresponde un mito de origen, que es a su vez la base de una lectura del mismo relato que llega a tener una determinada función en otro tipo de discurso aparentemente diferente, como sucede en el caso particular de la tragedia griega que acude a esos mitos. Incluso, en algunos casos, el relato que habla del origen de las cosas se aprecia como un desprendimiento directo de la cosmología, de modo que no siempre es clara la división entre un relato y otro en lo que se refiere al quid del pensamiento expuesto. En efecto, una vez explicado el origen del cosmos, los mitos subsecuentes operan como una explicación cada vez más intrincada de sus elementos, en razón de las diversas relecturas que se desarrollan a lo largo del tiempo, tal como sucede con algunos pasajes de la tragedia esquilea que más adelante se comentan. 
El mito cosmológico explica y establece un orden del mundo; dicho ordenamiento es la base del desarrollo social del ser humano, ${ }^{3}$ por lo que la edificación de los mitos y de los discursos posteriores a la cosmología responde a los relatos primigenios de toda cultura. Cuando ambos relatos mitológicos no concuerdan en la consecución de los hechos narrados, en el marco del tiempo mitológico, y entran en contradicción con el tiempo histórico, sobreviene casi de modo natural otro discurso que distingue y trata de subsanar la fricción entre los diferentes puntos de vista. En este sentido, es posible hallar en Esquilo una lectura poética -trágicaque a través de la reelaboración de un mito de origen expone también cierta cosmología: la confrontación aludida es, en efecto, una de las aristas que funciona en la comprensión de lo trágico. ${ }^{4}$ La significación de la tragedia no solo se genera porque en el sujeto hay una crisis de su existencia en los límites de su individualidad, sino también porque en el cosmos se experimenta tal oposición que afecta de diverso modo al ser humano. Basta con observar cómo el pensamiento cosmológico que deviene en un postulado religioso no concuerda, en un momento dado, con la evolución de la sociedad en otros órdenes como el filosófico y otros aparentemente distantes de este, como el político, por ejemplo. ${ }^{5}$

Pues bien, se parte del supuesto de que esta manifestación de lo trágico se presenta en donde la cosmología y la evolución sociopolítica entran en disparidad temporal, pues mientras que las explicaciones del cosmos se mantienen a lo largo del tiempo -acaso con modificaciones menores a causa de la oralidad primigenia de los mitos-, los relatos de origen, por su parte, llevan a cabo una reelaboración de dichos mitos de acuerdo con su propio contexto. Sin embargo, llega un momento en que se presenta la ruptura entre el tiempo del mito y el tiempo en el que se da su relectura. La tragedia esquilea es una muestra de este fenómeno que se manifiesta a través de los mecanismos de la tragedia, cuando esta modifica la sustancia de los mitos referidos acorde con las ideas propias del espacio donde se desarrolla. El cosmos es la respuesta a la complejidad del mundo que los pensadores presocráticos intuyeron a través de los elementos de la $\dot{\alpha} p \chi \dot{\eta}$, que rechaza el azar como regulador de todo cuanto existe. ${ }^{6}$ Esta misma reflexión que explica el orden físico se puede encontrar en la poesía esquilea, en donde se conjuga la visión de los componentes naturales con aquellos que son propios del orden social vigente en ese momento, particularmente en el Prometeo encadenado. ${ }^{7}$ De esta manera es factible observar el puente por el que transita el pensamiento enfocado en la phýsis para dar paso a la filosofía centrada en el ser humano, que tiene fuertes resonancias temáticas de índole filosófica y política en la tragedia. ${ }^{8}$

En efecto, en las piezas de Esquilo con cierta recurrencia se hallan huellas de la cosmología que se entreveran con el desarrollo de la tragedia. Se observan, por lo menos, dos momentos en los que ocurre dicho encuentro temático y ambos corresponden a la evolución del pensamiento filosófico: primero, el de la elucubración en torno al origen del cosmos a través de los diversos elementos que lo componen y, segundo, el período mitológico que va de los dioses pre-olímpicos al advenimiento de Zeus como dios supremo y símbolo de la justicia $(\Delta i \kappa \eta)$. En este último caso hay una correspondencia diáfana entre el pensamiento religioso y el socio-político en el marco de la democracia ateniense de mediados del siglo $\mathrm{V}$ a. C. Uno y otro aparecen alternadamente y entretejiéndose. No es, entonces, que el poeta siga necesariamente la secuencia de las generaciones de los dioses, sino que, por ejemplo, las advocaciones a la Tierra $(\Gamma \tilde{\eta} \text { o } \mathrm{X} \theta \dot{\omega} \nu)^{9}$ se hallan en el mismo espacio temporal que Zeus y que las Erinias, es decir, prácticamente el principio y el fin generacional de la génesis divina en el panteón griego. $\mathrm{Y}$, en medio de esta, se encuentra una de las muchas maneras en la

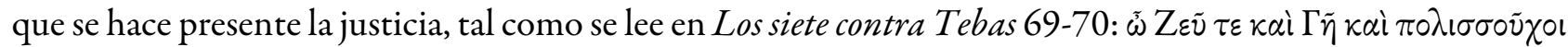

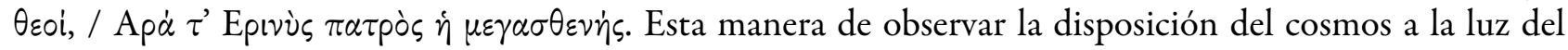
pensamiento presocrático muestra la evolución que va de las deidades primigenias hasta el concepto religioso y jurídico de la Dike, como ente que encarna la voluntad de Zeus, a la par del desarrollo del esquema de las trilogías de Esquilo. En efecto, Herington ha propuesto analizar las piezas de Esquilo en dos grupos bajo la idea del cosmos: el primer conjunto de tragedias estaría conformado por Persas y la tetralogía tebana, de la cual la única pieza conservada es Los siete contra Tebas (se han perdido Edipo, Layo y el drama satírico La Esfinge), en las cuales "is a simple and stable cosmos, one in which, to put in bluntly, the Divine is united 
against man”. ${ }^{10}$ En el segundo grupo de tragedias formado por las trilogías Orestiada y Prometeida y por la tetralogía Danaides, la imagen del cosmos es totalmente opuesta a la expresada en el primer grupo: "The human and divine cosmos is divided into the enemy camps of male and female, and the opposites which them respectively: light/dark, heaven/earth, new/old; the universal fabric is torn in two". ${ }^{11}$ Sin embargo, si bien la oposición en torno a la imagen del cosmos que propone Herington pone de manifiesto la evolución de las ideas sobre los dioses y el cosmos en la tragedia esquilea, también es posible, por el contrario, observar que en las trilogías apuntadas la oposición de los elementos no es absoluta, sino que dependen de la voluntad de Éros y de Neîkos, si se sigue el pensamiento de Empédocles, como se verá enseguida.

Así pues, ¿̇cómo explicar la evolución de un orden basado en los componentes de la naturaleza ante los cambios políticos y jurídicos que Esquilo vivió en la naciente y pujante democracia ateniense? Algunos estudiosos afirman que la cosmología es un estado primigenio en la totalidad del pensamiento mitológico de los pueblos, ${ }^{12}$ cuando lo cierto es que tal condición está presente constantemente en el desarrollo humano de todos los tiempos, pues incluso en las sociedades más avanzadas de la modernidad se precisa de una cosmología, ${ }^{13}$ cualidad que de primera intención parecería fuera de lugar dados los notables avances tecnológicos, pero que es esencial en la definición del ser humano. Es el caso de la Orestiada, por ejemplo, en el que el orden de los Titanes tiene que ser reformado en el pensamiento religioso griego dado el desfase en los modos de hacer política y de hacer justicia. Así, Esquilo sitúa la modificación y el arreglo de la visión cosmológica en el Areópago, en un tribunal judicial que fue un componente relevante de la democracia, para trocar a las Erinias en Euménides: como la justicia está unida naturalmente a lo divino, cualquier acto injusto deviene en impiedad. Esta característica se corresponde claramente en el orden socio-político, pues toda injusticia cometida en el seno de la pólis en sentido lato deviene, a su vez, en una falta cívica. Así, las antiguas deidades, cósmicas, fueron relevadas por los nuevos dioses, bajo una mirada de índole jurídico-social. ${ }^{14}$ De este modo, la metamorfosis de los dioses en la tragedia esquilea es una analogía en la que están inmersos los cambios socio-políticos. ${ }^{15}$

Quizá las estancias de Esquilo en Sicilia hayan sido el momento en el que este poeta tuvo mayor contacto con el pensamiento presocrático, en especial con Empédocles y con las teorías de los médicos de la Magna Grecia. ${ }^{16}$ Aunque se puede afirmar, de modo general, que Empédocles es un filósofo trágico, como lo ha definido Nietzsche, y que, por esta cualidad, algunas de sus ideas serían comparables con las de cualquiera de los tres poetas trágicos, es más evidente la cercanía con el pensamiento de Esquilo que con el de Sófocles y, menos aún, con el de Eurípides. ${ }^{17}$

Veamos algunas cuestiones al respecto. Empédocles habla de la presencia de todos los dioses y de los daimones en la naturaleza: su existencia es casi semejante a la de los hombres. La idea de este pensador de que los seres humanos son dioses caídos bien puede considerarse como una definición del sujeto trágico: ò $\lambda \beta \varepsilon ~ k \alpha i$

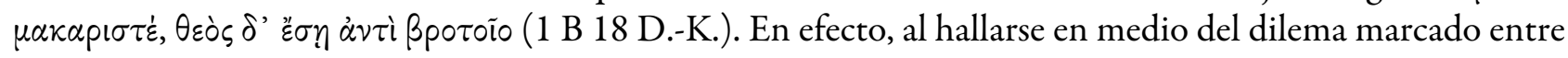
dios y el hombre y frente al error que desemboca ineluctablemente en la tragedia, el ser humano padece el dolor de quien ha sido abandonado por la naturaleza superior y se siente arrojado en un espacio inconcebible. Empédocles decía que el fuego, al separarse, dio origen a los nocturnos hijos de los hombres y de las lacrimosas mujeres (31 B 62 D.-K.), y a partir de esto es lícito suponer que se inició el tránsito incesante que acomete al género humano en su paso por la vida. ${ }^{18} \mathrm{El}$ héroe es un ser en vías hacia lo divino, pero su cualidad trágica lo ciñe irremediablemente a la condición humana. Si esto es así, Prometeo es el mejor ejemplo en la tragedia griega: un dios y acusadamente un Titán que ve su majestad divina denigrada por robar el fuego. Y en su caso, no solo ya el error es el robo de este elemento, sino que Esquilo hace notar que este hijo de Gea es un filántropo, ${ }^{19}$ esto es, un dios que ama a los hombres al punto de robar el fuego para ellos y ser denigrado frente a los dioses y los seres humanos. Y, al actuar de esta manera, se opone al cosmos pergeñado por Zeus, pues la naturaleza de Prometeo apunta hacia los efímeros, mientras que el del Cronida se refiere a la condición circular en el marco de un pensamiento religioso. En otras palabras, en el marco de las ideas religiosas hay una 
visión del eterno retorno, que en Prometeo encadenado se aprecia en el viaje de Ío y en la inmovilidad del Titán al estar atado a la montaña escita, ${ }^{20}$ hecho que se representa a lo largo de toda esta tragedia; y, por otro lado, hay un choque entre la tiranía y la democracia, aunque no se menciona explícitamente en el texto este último concepto, pero las continuas referencias a Zeus como tirano son más que evidentes para que el espectador indujera una especie de encomio a la democracia. Entonces, el Prometeo esquileo fue pergeñado como un dios en busca de la heroicidad humana, alejándose de la condición divina. Es elocuente que, de modo semejante,

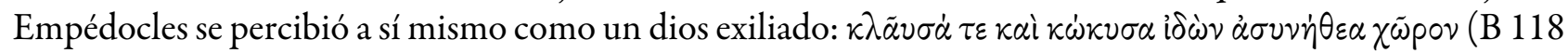
D.-K.). La tragedia del Titán, por su parte, se expresa también a través de su naturaleza filantrópica: al amar al hombre, se aleja más de los dioses y adquiere rasgos acusadamente humanos. Por tales razones es lícito pensar que se trata también de una deidad que representa la búsqueda de los hombres comunes, hecho único en el panteón griego. A lo dicho por Herington en cuanto a las oposiciones en el cosmos, hay que añadir la lucha dios/dios, Zeus/Prometeo.

En efecto, si el hombre es un continuo sufrir y el mundo es contradictorio e inestable, Empédocles encuentra en el amor, a través de la figura de Afrodita, el elemento cósmico que es capaz de unir lo que se ha separado, de crear a partir de dos cosas que se unen. La pulsión amorosa unifica; lo contrario, veíkos, correspondería a la tragedia (Emp. 31 B 21 D.-K.):

El auténtico principio motor continúa siendo siempre la $\phi i \lambda i \alpha$ y el $\nu \varepsilon \tilde{\kappa} \kappa \varsigma$, es decir, existe una relación necesaria entre sus efectos y la forma de las cosas. Las materias deben estar mezcladas y formadas de tal modo que sean parecidas y se correspondan; entonces se les añade la $\phi i \lambda i \alpha$. Sin embargo, lo que originariamente da forma a las cosas es el azar, la $\dot{\alpha} \nu \dot{\alpha} \gamma \kappa \eta$, no una especie de inteligencia. ${ }^{21}$

Siendo esto así, es posible observar, comparativamente, que el plan que guía las trilogías de Esquilo es la restauración del cosmos que, en sentido amplio, equivaldría a los conceptos del filósofo de Acragas: philía, philótes, Kýpris o Aphrodíte, esto es, la unión de aquellos elementos que, en tanto premisa de las trilogías, se presenta como veĩxos. Así, por ejemplo, Orestes cumple con la antigua regla sustentada por Apolo que exige vengar el asesinato de su padre, no obstante que ello significa ultimar a Clitemnestra, su madre; y luego de la persecución de las Erinias, el cosmos tiene lugar en un juicio que, a pesar de que fuera por un solo voto, el

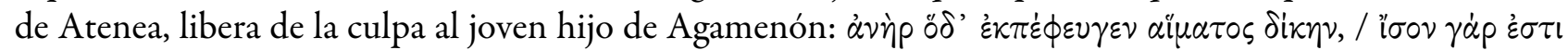
$\tau \dot{\alpha} p \dot{\theta} \theta \mu \eta \mu \alpha \tau \tilde{\omega} \nu \pi \dot{\alpha} \lambda \omega \nu .{ }^{22}$

Sin embargo, lo esencial es que, aunque por estrecho margen, el cosmos es recuperado y con ello se marca también el límite humano de la justicia. De igual modo, a pesar de que solo se conservan fragmentos de la tercera tragedia de la Prometeida, se colige que Zeus habría de hacer la paz con el Titán, y el orden roto, simbolizado por el robo del fuego, sería recompuesto. ${ }^{23}$ Por lo que respecta a las Danaides, el orden ha quedado roto por el rechazo al casamiento de estas doncellas con sus primos, esto es, la negación de los favores de Cipris, lo cual evidencia una clara situación de hýbris. Pero hay una base para esta acción: las hijas de Dánao son descendientes de Épafo, el nacido por el toque de Zeus a Ío, ${ }^{24}$ esto es, una concepción sin mancha, de ahí que las Danaides deseen conservarse puras y por ello asesinan a sus primos en la noche de bodas. La muerte de los egipcios conduce a la salvación inicial de mantener la pureza de las doncellas y para purificarlas del crimen la intervención de Apolo y Hermes es necesaria para restablecer el cosmos. ${ }^{25}$ Se puede afirmar, entonces, que hay una similitud en el proceso de movimiento y reconstitución del cosmos en el planteamiento de Empédocles y en la tragedia de Esquilo. En este caso, el poeta trágico habría considerado tal pensamiento como esquema del devenir trágico: la trilogía se presenta como silogismo, cuya conclusión deviene en el cosmos como oposición del caos. Específicamente, la disconformidad entre Zeus y Prometeo es el nudo de la tragedia que puede ser entendida del siguiente modo:

The four elements are here conceived of as actual forces pervading and trascending both the world of man and the sphere of the gods. Therefore, when god strives against god before the judgement seat of Ananke, the battle may well be staged in the mysterious realm of these elemental powers. ${ }^{26}$ 
Sobre esta misma idea, la filantropía es descrita como un hábito de Prometeo (A., Pr. 11; 28). Se trata de la configuración de un êthos peculiar para un dios griego, pues la característica que define a esta deidad es la naturaleza de amar al género humano, en oposición a la esencia de Zeus, cuyo êthos cobra sentido en las personificaciones de Cratos y de Bía -cuya unidad se puede comprender como el poder violento-, equivalentes en unidad a $\nu \varepsilon \tilde{i}$ cos, de acuerdo con el pensamiento de Empédocles y, de otro modo metafórico, correspondientes de las Erinias, persecutoras de Orestes. De manera concreta la violencia de Zeus en el Prometeo encadenado se proyecta en la reiteración de que el Cronida es un tirano caracterizado por la inexperiencia para gobernar y en el ejercicio de la venganza como forma de hacer justicia. La inclinación de Prometeo hacia los seres humanos no es algo circunstancial o providencial, pues el continente semántico de

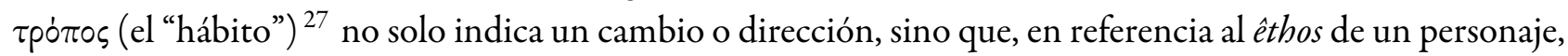
involucra un modo de ser dinámico, en este caso particular acorde con las ideas políticas y filosóficas de la democracia. ${ }^{28}$ Ya Hesíodo definía un carácter $\grave{\alpha} \gamma \kappa \nu \lambda \circ \mu \eta \dot{\tau} \eta$ s para el Titán y describía los efectos nocivos que esta forma de ser provocaba entre los dioses y directamente el perjuicio que causaba a los hombres. ${ }^{29}$ Sin embargo, de acuerdo con la visión de Esquilo, Prometeo resulta ser todo lo contrario de lo dicho por el poeta beocio, pues de una suerte de antihéroe deviene en una deidad filantrópica, bienhechora de la humanidad al regalarle el fuego gratuitamente; en todo caso, es a partir de esta tragedia, que el Titán es visto como el único dios filantrópico del panteón griego.

Si para Empédocles el hombre cae en una circunstancia caótica y el cosmos se desmorona, para el autor de Prometeo encadenado dicho orden estaría roto a partir del modo de actuar de Zeus, quien pretendía que los hombres perecieran al quitarles el fuego, de acuerdo con Hesíodo, ${ }^{30}$ cuestión que Esquilo habría expuesto con mayor detalle en el Prometheús Pýrforos, primera pieza de la Prometeida. ${ }^{31}$ Es entonces cuando el trópos filantrópico del Titán marca la pauta para el restablecimiento de la naturaleza en dirección hacia lo humano y, luego, según el plan performativo de Esquilo, el cosmos se recompondría en relación con los dioses olímpicos, en el momento en el que Zeus y Prometeo hicieran la paz, hecho que se habría escenificado en el Prometheús lyómenos, tercera pieza de la trilogía. Siendo esto así, Prometeo es un nexo que tensa y equilibra el cosmos como signo de la $\phi i \lambda i \alpha$, siguiendo el planteamiento de Empédocles.

La $\phi \lambda \lambda i \alpha$ indica la recomposición cósmica al equilibrar los elementos de la naturaleza. En este sentido, hay también una similitud entre Empédocles y Esquilo en lo que se refiere a los cuatro elementos del cosmos y su relación con lo trágico. El pensador de Acragas se lamenta de su situación próxima a lo humano y para ello alude al aire (éter), al agua (el mar), a la tierra y al fuego (el sol): los elementos revelan así la cercanía de lo divino con lo humano. Al ser exiliado del ámbito divino, Empédocles se ve sumergido en un ciclo que transita de un elemento a otro hasta que deja de ser una divinidad y se convierte en un simple mortal. ${ }^{32}$ Así se originaría, también, la raza humana que el filósofo definió, en un tono sentencioso que recuerda a Hesíodo

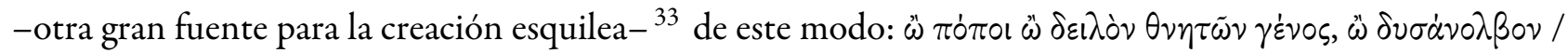

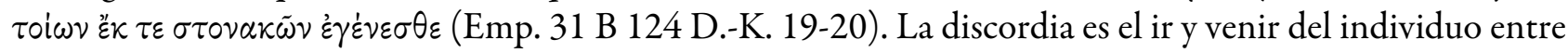
los cuatro elementos, pero en Esquilo este movimiento y tales componentes obedecen a una interpretación de lo trágico en un sistema de creencias religiosas y políticas, de modo que, como ha hecho notar Vidal-Naquet, la tragedia principia cuando se quebranta el cosmos de la pólis, esto es, cuando aparece la violencia y destruye la política. ${ }^{34}$

Hay que recordar que la imagen del exilio concuerda con el tópico que aparece en la tragedia cuando el personaje trágico se ve en la necesidad de escapar, generalmente, porque es expulsado con violencia y enviado a un mundo hostil. Los casos de Orestes y de Ío son los ejemplos que comprueban esta sugerencia en la obra esquilea, el primero huyendo de la muerte atroz a manos de las Erinias y la segunda errante y errada como castigo gratuito por la pasión que Zeus siente por ella. Sobre todo este último caso, el periplo de Ílo en el mundo de la barbarie es sintomático para entender la expulsión sin fundamento, pues la doncella lleva a cabo un viaje que denota un rito de iniciación y que, efectivamente, culmina con su deificación. Ío es objeto de una 
metamorfosis violenta que es equiparable a una metempsicosis: de ser humano es transformada en vaca por intervención divina a fin de que pueda realizar un viaje de iniciación en un espacio pleno de barbarie, para adquirir luego la naturaleza propia de una deidad. ${ }^{35}$ El estadio en vaca es el proceso necesario que lleva a Ío a una transmigración del alma humana para acceder al carácter divino. ${ }^{36}$ Etéocles, en el inicio de Los siete contra Tebas (vv. 4-5) plantea, de manera sencilla, la delgada línea que hay entre el ser considerado prácticamente un dios y un mero hombre, pues el triunfo o el fracaso en la guerra es lo que determina tal condición: $\varepsilon \dot{l} \mu \varepsilon \dot{\varepsilon}$

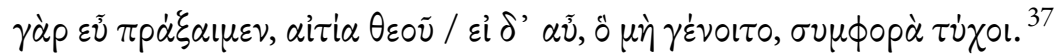

Pues bien, por lo que toca específicamente a los cuatro elementos aludidos en la conformación del cosmos y su sentido trágico, a partir del verso 88 se lee en Prometeo encadenado una invocación del Titán a los componentes de la naturaleza y así inicia su monólogo en la primera escena de dicha tragedia: ${ }^{38}$

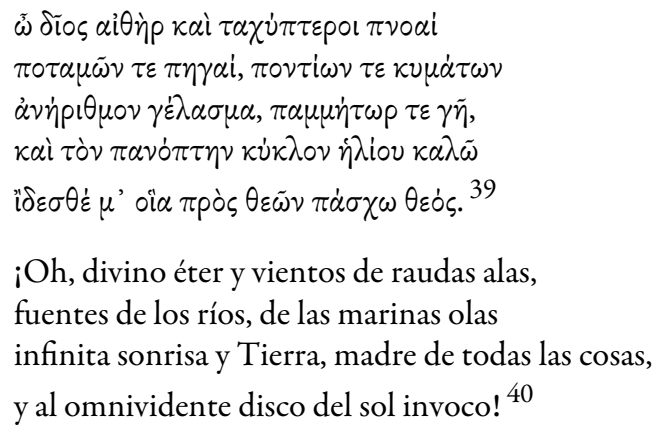

El éter es aquello que se halla entre la tierra y el cielo, pero, extensivamente, se puede aludir solo a este último cuando se hace referencia a la parte celeste más alta y pura. En el pensamiento presocrático, había una estrecha relación entre el éter y la acción del fuego ( $\alpha^{\prime} \theta \omega$, "quemar", "abrasar", "inflamar”). De acuerdo con Chantraine, el origen y el sentido filosófico de esta palabra proviene ya desde la tradición india y china, en donde el vínculo éter-fuego ya está atestiguado (la raíz indoeuropea aith- es base del sustantivo al que nos referimos como $\alpha i \theta \dot{\eta} \rho$ y del verbo $\alpha i \theta \omega) .{ }^{41}$ De aquí que el éter sea un medio de purificación, pues como acto destruye todo aquello que resulta inmundo. La apelación a lo divino (jios) considera al éter como un ente sagrado en referencia a lo más alto e inalcanzable para el ser humano. ${ }^{42}$ En efecto, en la cúspide de todos los elementos descritos por el poeta está el fuego supremo, el "omnividente disco del sol"( $\pi \alpha \nu \dot{\pi} \pi \tau \eta \nu$

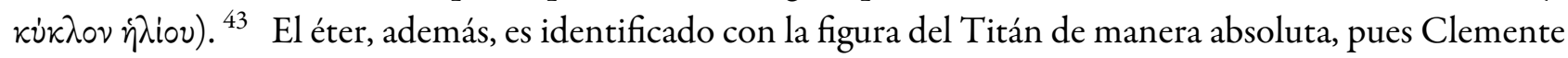
de Alejandría hace referencia a Prometeo al mencionar los cuatro elementos de la cosmología de Empédocles:

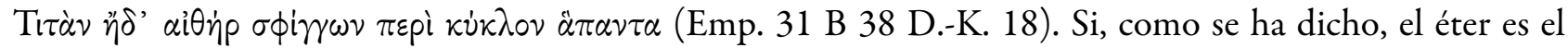
espacio que media entre la tierra y el cielo, cabe pensar, siguiendo a Adams, que este elemento es donde se confrontan las dos entidades, dios y el hombre: una suerte de campo de batalla en el que, como se manifiesta en el epílogo del Prometeo encadenado, los elementos entran en una convulsión, en una guerra que representa una colisión violenta entre los componentes que representan lo bajo y lo alto, respectivamente. La confrontación es evidente a lo largo de toda la obra: Prometeo, ladrón del fuego divino, versus Zeus, quien representa en sí mismo la tiranía, al arribar al poder de manera violenta y al ejercerlo del mismo modo:

In Prometheus's rebellion against Zeus we may see, on the one hand, an encapsulation of the historical struggle of the Athenians against tyranny or, on the other hand, a symbolic tableau of tension on the moral or cosmic plane. ${ }^{45}$

En el sentido político-cósmico definido por Konstan, Prometeo es una deidad y al mismo tiempo representa la parte humana que se confronta con lo divino a causa de la posesión del fuego, el elemento del cosmos que es motivo de la discordia, del mismo modo como se confrontan dos maneras distintas de ejercer el poder político. Si se sigue el aspecto político que enmarca estas ideas, de modo semejante como se expone en el Prometeo encadenado, se sabe que Empédocles fue enemigo de la tiranía: siendo muy joven vivió el tránsito de una tiranía violenta a la democracia. De acuerdo con Diógenes Laercio (VIII, 64), Empédocles 
no dudó en ordenar la ejecución del arconte que lo invitó a un simposio, en el cual el simposiarca obligó a los presentes a beber vino bajo la advertencia de que de no hacerlo serían bañados con la misma bebida, signo esto último del advenimiento de la tiranía. Asimismo, disolvió el Consejo de los Mil porque le pareció que eran sospechosos de estar a favor de la tiranía. ${ }^{46}$ Empédocles "llegó a ser tan popular que se le ofreció la $\beta \alpha \sigma i \lambda \varepsilon i \alpha$, cargo que rechazó. Después, tras haber establecido el orden en Agrigento, quiso acudir en ayuda de otras ciudades". ${ }^{47}$ Como se puede observar, hay coincidencia entre el pensamiento de Empédocles y el autor del Prometeo encadenado en torno a la oposición al sistema tiránico, pues ambos advirtieron que este era un esquema político que representaba la discordia social, hecho equiparable con la confrontación y la separación de los elementos del cosmos como causa o como analogía de la disputa entre lo divino y lo humano.

En cuanto al segundo elemento, el agua, Esquilo alude a $\pi \circ \tau \alpha \mu \tilde{\omega} \nu \tau \varepsilon \pi \eta \gamma \alpha \dot{i}, \pi \circ \nu \tau i \omega \nu \tau \varepsilon \kappa \nu \mu \dot{\alpha} \tau \omega \nu$ / $\dot{\alpha} \nu \dot{\eta} \rho 1 \theta \mu \nu \nu$ $\gamma_{\dot{\varepsilon}}^{\prime} \lambda \alpha \sigma \mu \alpha$ (vv. 89-90), donde se observa que, yendo de lo más alto a lo bajo, Prometeo involucra en su imprecación a todos los elementos del cosmos. El agua también fue considerada por los presocráticos como otro de los elementos generadores de todo cuanto existe. Las fuentes de los ríos son surtidoras del mar, de

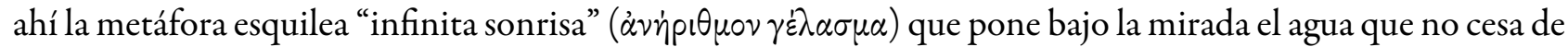
andar en su cauce, y puesto que aquellos veneros fueron paridos por Océano (el mar) y Tetis se colige que lo que dio vida se nutre de sí mismo. ${ }^{48}$ Quizá lo más significativo en torno a la mención del agua es que el Coro del Prometeo encadenado está conformado por las Oceánides, habitantes de las corrientes marinas, quienes mantienen una fuerte empatía a lo largo de la tragedia con el Titán, al punto de hacer suyo el sufrimiento de este y de acompañarlo en el nuevo castigo impuesto por Zeus: enviarlo al infierno.

Ya se ha señalado líneas arriba la presencia constante de la invocación a la tierra, "madre de todas las cosas" en el Prometeo encadenado. La idea de la tierra como generadora esencial, específicamente la que alimenta al cosmos, complementa la invocación a los elementos hecha por el Titán. De modo análogo, en Los siete contra Tebas Polinices se refiere a esta cuando llama a la defensa del país, entendiendo este término como la tierra, frente al enemigo porque es madre y nodriza. ${ }^{49}$ Pero Prometeo señala, además, que la Tierra $(\Gamma \tilde{\eta})$ es la madre de los Titanes, por tal razón el dolor de ella, personificada como matriz y ya no solo como simple elemento, adquiere una significación metafórica al llorar por el modo en que sus hijos, con Prometeo a la cabeza, han sido vencidos y sojuzgados por Zeus. ${ }^{50}$ Por ello también hay que llamar la atención sobre el vínculo natural y estrecho del Titán con su madre, pues la referencia a ella es por ser uno de los cuatro elementos primigenios y, al mismo tiempo, como la nutrición que otorga la vida. ${ }^{51}$

Ahora bien, la invocación de Prometeo contenida entre los versos 88 y 92 presenta una correspondencia con el cierre frenético de la tragedia: cuando el Titán es enviado al inframundo, en compañía de las Oceánides, los elementos lo acometen violentamente. El cataclismo en el que los cuatro elementos parecen destruir a Prometeo es una imagen poética que se asume como un castigo irrecusable. ${ }^{52}$ Se trata de una serie de elementos apocalípticos que es semejante a la descripción de Empédocles referida a la expulsión del dioshombre que cae en la tierra transitando de un elemento a otro:

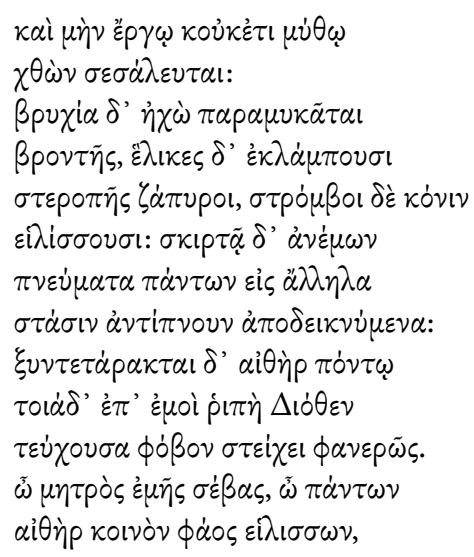




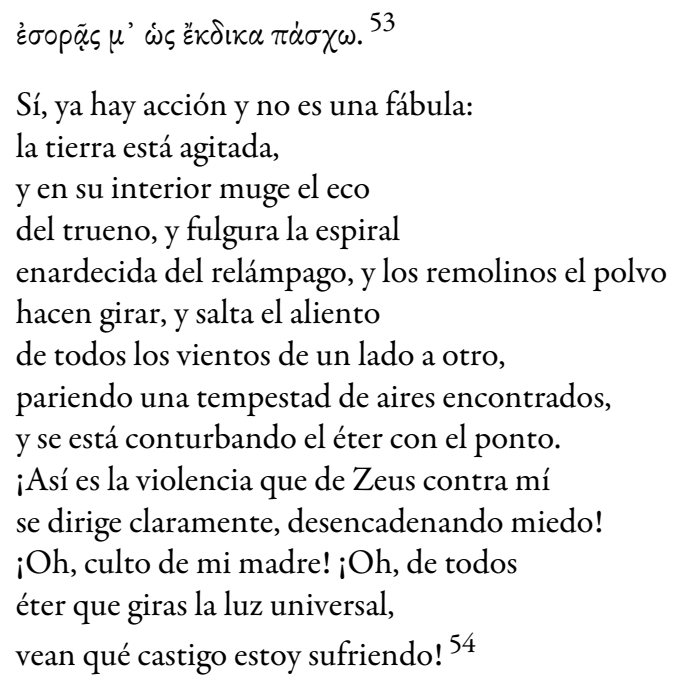

Para vencer al dios que dio un significado distinto al fuego, pues de elemento creador del cosmos llegó a simbolizar la fundamentación del pensamiento humano y del progreso, ${ }^{55}$ los cuatro componentes de la naturaleza unieron sus fuerzas para conducirlo a una muerte metafórica, en tanto que lo divino no puede ser aniquilado. Zeus utiliza los componentes elementales del cosmos como armas para atacar y tratar de doblegar a Prometeo, del mismo modo que usó el trueno, el rayo y la centella para vencer al resto de los Titanes. ${ }^{56} \mathrm{La}$ victoria es pírrica porque la cualidad de lo divino no se destruye: si en el Prometheús lyómenos el cosmos se reconstruye con la paz entre estos dos dioses, esta, como en la Orestiada, es una mera potencia, pues la raíz trágica persiste en razón de que la ley y el acuerdo subsanan la inmediatez del error trágico, pero este no es resuelto de fondo, porque la muerte de Clitemnestra, así como el robo del fuego son hechos consumados y concluyentes. Como el Titán conserva su condición divina, cabe pergeñar que el Cronida lo que busca aniquilar es la parte humana del dios rebelde: su êthos filantrópico. Así, lo humano es objeto de animadversión por los cuatro elementos que dan existencia a todas las cosas. Pero el legado del Titán ya estaba hecho: de acuerdo con la comprensión de Heráclito, el fuego era resultado del mar y luego de la tierra, en fases sucesivas, 57 de manera que se le consideraba como unidad de la naturaleza, idea que Esquilo resume en la comprensión del fuego como un $\delta \delta \delta \dot{\alpha} \sigma \kappa \alpha \lambda \circ \varsigma \tau \dot{\varepsilon} \chi \nu \eta \varsigma / \pi \dot{\alpha} \sigma \eta \varsigma,{ }^{58}$ incluida aquella técnica que otorga la razón a los hombres y que les permite progresar. En efecto, todas las cosas son una (fr. 50, Hipólito Refl. IX, 9, 1), y solo su conjunción las origina, modifica y proyecta. La desunión de los elementos del cosmos se entiende así como tragedia. Además, de tal conjunción participan todos los elementos, no obstante que la mayoría se comporta como si tuviera una existencia individual (fr. 2, Sexto, Ad. Math. VII 133).

Ahora bien, a pesar de que los cuatro elementos participan del cosmos y de la confrontación en conjunto, el fuego en tanto componente co-extensivo del lógos, y por la misma razón sinónimo del "constitutivo cósmico primario", 59 incorpora en sí mismo la tierra, el agua y el aire, de aquí que se le considere como centro de la controversia cósmica y, por extensión, el elemento donde son incluidos los aspectos de la vida humana. La oposición de los elementos solo puede ser posible si en un momento dado se unifican, tal como se explica en Agamenón, donde la oposición entre el fuego y el agua reflejan la unión de los contrarios:

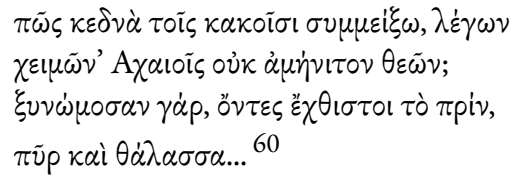

¿Cómo lo agradable con lo malo he de mezclar, si relato la tempestad iracunda de los dioses contra los Aqueos?

Pues se confederaron, a pesar de ser muy enemigos desde siempre, 
el fuego y el mar... 61

Por su parte, Damascio de Siria señala que Ferécides creía que del semen de Cronos emanaba el fuego, el viento y el agua (de principiis 124 bis, Kirk-Raven). Cada uno de estos elementos participa como principio generador de todo cuanto existe, considerando que antes de ellos existieron desde siempre Zeus, Cronos y Ctonia. La explicación cosmológica que revela cómo los elementos primarios del cosmos se producen a partir del semen es común en algunas cosmologías antiguas:

La idea de que el semen humano es generador y que, en consecuencia, el semen de una divinidad primaria es cosmogónicamente creador, no es ni sorprendente ni ilógica. Lo que, sin embargo, sorprende, en este caso, son los efectos de la producción, que tienen ciertas resonancias con la teoría de los cuatro elementos del siglo $\mathrm{V}$, con la omisión de la tierra, porque su mismo nombre Ctonia-Ge la define. ${ }^{62}$

Siendo esto así, uno de los ecos en los que se reproduce esta concepción presocrática del cosmos se encuentra bien definida en Prometeo encadenado, donde se lee:

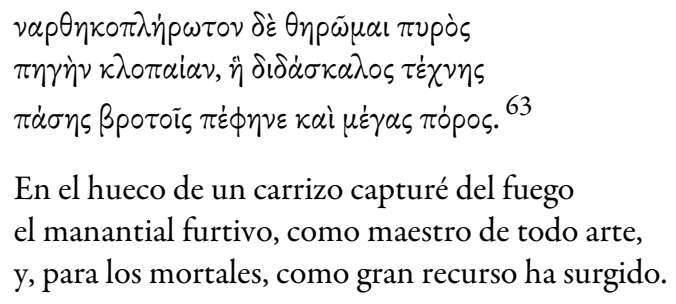

Si $v \alpha \rho \theta \eta \kappa o \pi \lambda \dot{\eta} \rho \omega \tau \circ \nu$ metafóricamente es una referencia al falo, entonces cabe la suposición que relaciona el $\nu \dot{\alpha} \rho \theta \eta \xi$, el carrizo o férula que, estando hueco, va pleno del fuego sagrado para ser entregado a los hombres. ${ }^{65}$ Dicho carrizo es una imagen figurada del falo de donde procede el fuego de los dioses, de acuerdo con lo que se infiere del Prometeo encadenado. Refiriéndose a este Titán y su vinculación con el mito de Pandora, Böhme señala que "fuego y sexualidad van ligadas, en su ambivalencia, el uno al otro: en la bendición del hogar, hacedor de comunidades, y en la maldición del deseo inextinguible, que no se deja 'domesticar', sino que despide salvajes llamas". ${ }^{66}$ Esto es, el fuego donado por Prometeo se vuelve la semilla que fecunda en la primera mujer, luego de la confrontación con Zeus y que es regalada por este junto con toda la cauda de males que aquejan al género humano. ${ }^{67}$

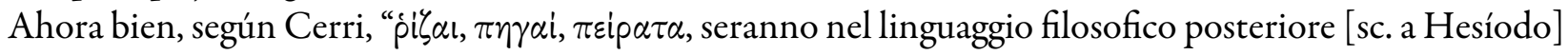
normalmente impiegati con lo stesso significato di ảp $\alpha \alpha$, ad indicare i semina rerum, le scaturigini prime, $i$ principi limitativi”. ${ }^{68}$ Entonces, si $\pi \eta \gamma \eta \dot{~ e s ~ u n a ~ m a n e r a ~ d e ~ r e f e r i r s e ~ a ~} \dot{\alpha} \rho \chi \dot{\eta}$, se deduce que $v \alpha \rho \theta \eta \kappa \circ \pi \lambda \eta \dot{\eta} \rho \omega \tau \sigma \nu$ es el principio generador, no solo de los elementos que componen las cosas, sino que se comporta también como el causante de los elementos culturales. Siendo esto así, el sentido metafórico de $\pi \eta \gamma \dot{\eta}$ en el verso 110

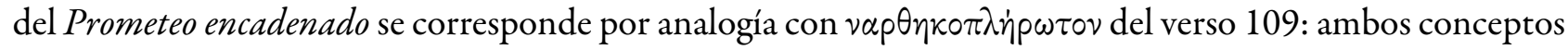
refieren la raíz del fuego donado a los seres humanos. ${ }^{69}$ De este modo, al llevar el $\nu \dot{\alpha} \rho \theta \eta \xi$ con el fuego divino para regalarlo a la humanidad, Prometeo deviene en símbolo donde se conjuntan los elementos del cosmos, teniendo como centro el fuego que marca el antes y el después en cuanto a la idea de progreso.

En suma, lo apuntado por Nietzsche en torno a Empédocles como un pensador trágico bien puede aplicarse a Esquilo, cuando el filósofo germano señalaba que en tal pensador se cruzan la época del mito y de lo orgiástico y la época del estadista democrático, del ilustrado y del hombre de ciencia. ${ }^{70}$ Desde el plano de la filosofía, Empédocles trazó una explicación cosmológica de los elementos, en el marco de la cual la confrontación se consideraba un motor de la creación y del movimiento. El hombre estaba sujeto a estos procesos y en el paso de un estado a otro necesariamente caía en el espacio de lo trágico en un momento dado; esta concepción trágica de Empédocles era compartida con Heráclito pues, según Plutarco, ambos pensadores consideraban que la necesidad y la guerra se mezclan en el progreso humano, sin dejar prácticamente nada 
que no tenga alguna mancha provocada por la injusticia. ${ }^{71}$ De modo semejante, la representación de los elementos, que Esquilo trazó en Prometeo encadenado, guarda relación con el pensamiento de Empédocles en cuanto a la comprensión del origen de la cosas y cómo el movimiento de estas es eterno frente al devenir de la sociedad, espacio en el que se explicaría también la confrontación de los seres humanos desde la perspectiva cosmológica. Filosofía y tragedia se vinculan de este modo para explicar, desde sus ámbitos, la cosmología creada por los cuatro elementos y su proyección en los avatares de la sociedad, tal como se observa en la política, donde de igual manera la descomposición social era producto del enfrentamiento y de la separación de sus componentes. Asimismo, se advierte cómo un pensamiento de corte mitológico sirve de base para entender la circunstancias que determinan los contextos políticos: los dioses y los hombres luchan en un sentido cósmico en el área común del éter; entre los hombres, la disputa se da en torno de las formas de gobierno, que representan la configuración del entorno socio-político a imagen y semejanza del cosmos, todo ello entendido bajo la metáfora del fuego, que para Heráclito es el orden natural, pues no es creación ni de dios ni de hombre, sino de tal elemento en sí mismo, que es eterno y se enciende y se apaga según medida (fr. 22 B 30 DK). Siendo esto así, el fuego, prerrogativa prometeica de los humanos, es un proceso dialéctico en sí mismo y, a partir de él, la naturaleza y la sociedad tienen su propio ritmo.

\section{BIBLIOGRAFÍA}

García Pérez, D. (2013) Esquilo: Prometeo encadenado, México.

García Yebra, V. (1974) Aristóteles: Poética, Madrid.

Gärtner, H. \& Marcovic, M. (1999) Diogenis Laerti Vitae Philosophorum, Stuttgart.

Kirk, G. S. y Raven, J. E. (1987) Los filósofos presocráticos. Historia crítica con selección de textos, Madrid.

Ross, W. D. (1927) Aristotle: Problemata, London.

Vianello de Córdova, P. (1978) Hesiodo: Teogonia, México.

Vianello de Córdova, P. (1979) Hesiodo: Los trabajos y los dias, México.

West, M. L. (1990) Aeschily: Tragoediae, Stuttgart.

Adams, S. M. (1933) "The Four Elements in the Prometheus Vinctus", CPh 28.2: 97-103.

Albini, U. (1975) "La funzione di Io nel Prometeo", PP XXX.CLXIII: 278-284.

Böhme, G. y Böhme, H. (1998) Fuego, agua, tierra, aire. Una historia cultural de los elementos, Barcelona.

Cerri, G. (2008) “L'ideologia dei quattro elementi nella cultura greca arcaica: dell'epos omerico alla scienza fisica”, en O. Álvarez (ed.) Cultura clásica y su tradición, México: 69-74.

Chantraine, P. (1968) Dictionnaire Étymologique de la Langue Grecque, Paris.

Conacher, D. J. (1980) Aeschylus' Prometheus Bound, Toronto.

Cornford, F. M. (1952) Principium Sapientiae: the Origins of Greek Philosophical Thought, Cambridge.

Eliade, M. (1998) Tratado de historia de las religiones, México.

Eliade, M. (1999) El mito del eterno retorno, Madrid.

Eliade, M. (2000) Aspectos del mito, Barcelona.

Griffith, M. (1977) The Authenticity of Prometheus Bound, Cambridge.

Hawking, S. W. (2013) Historia del tiempo. Del big bang a los agujeros negros, Barcelona.

Jaeger, W. W. (1952) La teología de los primeros filósofos griegos, México.

Kirk, G. S. (1990) El mito. Su significado y funciones en la Antigüedad y otras culturas, Barcelona.

Konstan, D. (1977) "The Ocean Episode in the Prometheus Bound", HR 17.1: 61-72.

Lesky, A. (1958) Die griechische Tragödie, Stuttgart.

López Férez, J. A. (1990) “Tragedia griega y pensamiento”, Epos 6: 13-35. 
Nietszche, F. (2011) “Los filósofos preplatónicos”, en Obras I, Madrid.

Petazzoni, R. (1967) “Myths of Beginnings and Creation Myths", en Essays on the History of Religions, Leiden: 11-23.

Reinhardt, K. (2010) Sófocles, Madrid.

Prométhée enchaîné

Sánchez Ruipérez, M. (1964) La aparición de la idea de progreso en Grecia, Madrid.

Seaford, R. (2003) “Aeschylus and the Unity of Opposites”, JHS 123: 141-163.

Solmsen, F. (1995) Hesiod and Aeschylus, Ithaca \& London.

Vernant, J. P. (2006) Pandora, la première femme, Paris.

Vidal-Naquet, P. (2004) El espejo roto. Tragedia y politica en la Grecia antigua, Madrid.

West, M. L. (1979) “The Prometheus Trilogy”, JHS 99: 130-148.

White, S. (2001) "Io's World: Intimations of Theodicy in Prometheus Bound", JHS 121: 107-140.

Winnington-Ingram, R. P. (1961) “The Danaid Trilogy of Aeschylus”, JHS 81: 141-152.

\section{Notas}

1 Proyecto "El coro trágico: su función y evolución en las tragedias griega y latina y su traducción en la dramaturgia occidental”, FFI2015-63836. Universidad de Valencia, España.

2 Eliade (2000: 29).

3 Petazzoni (1967: 11-23).

4 Lesky ha señalado con acierto que los griegos crearon la tragedia como una gran obra del arte, pero no desarrollaron una teoría de lo trágico, esto es, no fueron más allá de la estructuración de la tragedia (Lesky, 1958: 29). A nuestro parecer, el tema de los elementos del cosmos es parte de esa teoría de lo trágico que Esquilo expone a lo largo de las piezas que de él se conservan.

5 En el marco de la tragedia griega el ejemplo más acusado en cuanto a la oposición de los discursos que tocan lo mitológico, lo religioso y lo político quizá sea el que se halla en la Antígona de Sófocles, donde la doncella defiende la ley natural (phýsis) frente a la ley del ser humano (nómos), expuesta por Creonte, el rey tebano. Esta oposición implica una tragedia de dimensiones cósmicas. Al respecto, Reinhardt (2010: 90-91) escribió: “Antígona (...) no está poseída por el dios como una fuerza que la impulse a la acción. Lo que, sin embargo, sí la posee es la certeza que le asegura que al igual que la comunidad humana tiene sus tribunales para castigar a los culpables, asimismo los dioses disponen de los suyos, aunque dónde y cómo ella no pueda precisarlo; si quisiera pronunciarse de forma más precisa, pasaría entonces ilícitamente de lo humano a lo divino".

6 Cornford (1952: 3-11).

7 La fecha de composición del Prometeo encadenado es uno de los problemas clave para indicar la paternidad de la pieza trágica: si se toma en cuenta que en los versos 351 y ss. el autor hace referencia a la erupción del Etna que sucedió entre el 479 y el 475, es posible establecer el terminus post quem poco después de estos años. El terminus ante quem ha sido fijado en el 415, pero lo más probable es que sea anterior al 424, año en el que los Caballeros de Aristófanes fue representada, pues hay una clara parodia de esta comedia en los vv. 758 y ss. y 863 respecto de Prometeo encadenado vv. 59,308 y 613. Cf. Griffith (1977: 11-12). Tanto 415 y 424 son años que escapan a la vida de Esquilo, pues murió en Gela en 456.

8 La propuesta de este trabajo guarda cierta relación con la siguiente hipótesis de Seaford (2003: 141): “This is an essay in the interconnectedness of phenomena generally considered separately: verbal style, ritual, tragic action and cosmology. Their interconectedness will emerge from the idea of the unity of opposites".

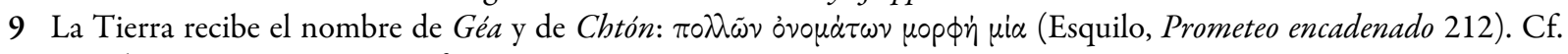
Esquilo, Agamenón 1537; Coéforas 127, 396-398.

10 Herington (1967: 80).

11 Herington (1967: 81).

12 Kirk (1990: 15-44).

13 Así, por ejemplo, Stephen W. Hawking (2013: 32) explica por qué la humanidad de todos los tiempos siempre se cuestionará el origen y composición del cosmos: "Hoy en día, aún seguimos anhelando saber por qué estamos aquí y de dónde venimos. El profundo deseo de conocimiento de la humanidad es justificación suficiente para continuar nuestra búsqueda. Y esta no cesará hasta que poseamos una descripción completa del universo en el que vivimos".

14 Solmsen (1995: 178 y ss.). Cf. López Férez (1990: 18-19). 
15 Es oportuna aquí la siguiente explicación de Mircea Eliade (1999: 43): "nos hallamos frente a la concepción de una élite que interpreta la historia contemporánea por medio de un mito. Se trata pues, de una serie de acontecimientos contemporáneos que están articulados e interpretados conforme al modelo atemporal del mito heroico".

16 Herington (1967: 74-85) documenta como seguras dos estancias de Esquilo en Sicilia y discute otras posibles a partir de diversas fuentes directas.

17 Nietzsche (2003: 133-134): "Empédocles es el filósofo trágico, contemporáneo de Esquilo. Lo más notable de este filósofo es su extraordinario pesimismo, algo que, sin embargo, no opera en él de manera estática, sino de manera extraordinariamente activa".

18 Anaximandro expone, según Ps. Plutarco (Stromata 2; Kirk-Raven 1987: 124), que de la confrontación entre lo caliente y lo frío nació una esfera o llama de fuego que circundó la tierra. Dicha esfera se rompió dando lugar al sol, la luna y las estrellas; de ahí que los cuerpos celestes son círculos de fuego.

19 Esquilo, Prometeo encadenado 11, 28.

20 Esquilo, Prometeo encadenado 700-741, 786-876.

21 Nietzsche (2003: 138).

22 Esquilo, Euménides 753-754.

23 "The liberation of Prometheus in the Prometheia, modelled on the mystic passage of the individual soul, brings permanent blessings for all humankind. Similarly the liberation of Orestes brings to the Athenian polis blessings (the cult of the Erinyes, the law court, the alliance with Argos) whose permanence is repeatedly emphasized", Seaford (2003: 157).

24 Cf. Esquilo, Prometeo encadenado 848-861.

25 Cf. Winnington-Ingram (1961: 141-152).

26 Adams (1933: 97).

27 Esquilo, Prometeo encadenado 11.

28 La construcción del $\hat{\eta} \theta 0 \varsigma$ en la práctica de la retórica griega se realizaba dinámicamente en el discurso, esto es, el personaje en cuestión edificaba su carácter a través de sus palabras, a diferencia de la auctoritas de la oratoria latina que de antemano ya consideraba la forma de ser del orador. Cf. Aristóteles, Problemas XXIX 920a 6; XXX 953a 5; Poética 1450a 5-21. Sobre el $\tilde{\eta} \theta 0 \varsigma$ de Prometeo, cf. la descripción hecha por Océano: Esquilo, Prometeo encadenado 320-324.

29 Hesíodo, Los trabajos y los dias 47 y ss.; Teogonia 545 y ss.

30 Hesíodo, Teogonía 565-570; Los trabajos y los dias 50-58.

31 "If Pyrph. came first, it dealt with Prometheus' theft of fire. The plan of the trilogy was then Crime-PunishmentReconciliation. This, and not Punishment-Reconciliation-(?), is surely the scheme that would naturally have occurred to the poet”, West (1979: 131).

32 Nietzsche (2003: 136) apunta lo siguiente: "La migración a través de todos los elementos es el equivalente científiconatural de la metempsicosis de Pitágoras. Empédocles mismo declara haber sido ya un ave, un arbusto, un pez, un muchacho y una muchacha".

33 Cf. Hesíodo, Los trabajos y los días 106-201. El poeta beocio vinculó temáticamente el mito de las cinco razas con el mito de Prometeo al establecer la injusticia como causa de la decadencia humana.

34 Cf. Vidal-Naquet (2004).

35 Esquilo, Prometeo encadenado 561-886. Cf. White (2001: 107-140).

36 Albini (1975: 280): "il colloquio Prometeo-Io-Coro estende la situazione, la fissa in dimensione cosmiche". La dimensión cósmica que propone Albini para leer el pasaje aludido se sostiene en las características esenciales del personaje mismo: Prometeo, al ser un dios, no está sujeto al tiempo y, por lo mismo, la inmortalidad le permite hablar de una situación metafísica. Sin embargo, a la observación de Albini hay que añadir que la temporalidad del relato entra en los terrenos propios del mito, y desde ahí se puede comprender la serie de acciones que tienen lugar en el presente. Es decir, en el momento en que Ío y Prometeo dialogan, con el coro como acompañante, el mito echa a andar el tiempo sin tiempo, por lo que las historias se hacen presentes en cualquier momento.

37 Eurípides plantea en el epílogo de su Electra que Orestes tiene que salir al exilio para expurgar su matricidio y, solo una vez que haya sido purificado, podría regresar a Argos para tomar el poder que le corresponde.

38 Cerri (2008: 69-74) hace recordar que la presencia de los cuatro elementos por medio de las divinidades (Gea, Zeus, Helios, etcétera) aparece ya en la poesía homérica y en la hesiódica.

39 Esquilo, Prometeo encadenado 88-92.

40 García Pérez (2013: 315-317).

41 Chantraine (1968: s. v. $\alpha i \theta \omega)$.

42 Cf. Eliade (1998: 57-59).

43 Cf. Adams (1933: 97).

44 Adams (1933: 99).

45 Konstan (1977: 61-72). 
46 Diógenes Laercio, Vidas de los filósofos más ilustres VIII, 66.

47 Nietzsche (2011: 278-279).

48 Hesíodo, Teogonía 337 y ss.

49 Cf. Esquilo, Los Siete contra Tebas 15 y ss.

50 Esquilo, Prometeo encadenado 416 y ss.

51 La invocación que hace la Pitia en los primeros dos versos de Euménides coloca en primer término a la Tierra, antes que

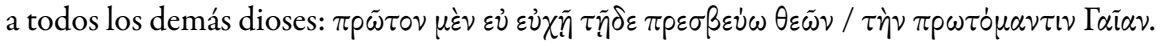

52 Los eventos naturales que destruyen la naturaleza humana se interpretan como la justicia que aplican las deidades a causa de las acciones de los hombres. Es una manera, entonces, de explicar la culpa. Cf. Böhme y Böhme (1998: 74-77).

53 Esquilo, Prometeo encadenado 1080-1093.

54 García Pérez (2013: 285).

55 Cf. Sánchez Ruipérez (1964: 16, 24).

56 Esquilo, Prometeo encadenado 219-220.

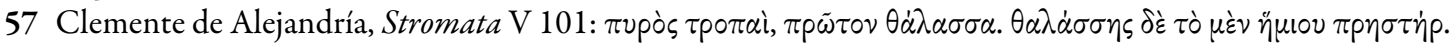

58 Esquilo, Prometeo encadenado 110-111.

59 Kirk y Raven (1987: 274). Para Jaeger (1952: 29) Anaximandro presentó el primer cuadro unificado y universal del mundo a partir de la deducción y de la explicación natural de los fenómenos.

60 Esquilo, Agamenón 648-651.

61 La traducción es nuestra.

62 Kirk y Raven (1987: 68).

63 Esquilo, Prometeo encadenado 109-111.

64 García Pérez (2013: 139).

65 Acerca del sentido de $v \dot{\alpha} \rho \theta \eta \xi$, cf. Hesíodo, Teogonía 566; Los trabajos y los dias 50 y ss.

66 Cf. Böhme y Böhme (1988: 86).

67 Cf. Vernant (2006: 18-24).

68 Cerri (2008: 70-71).

69 En los otros tres casos en los que aparece $\pi \eta \gamma \eta \dot{~ e n ~} P r .89,401,434$ y 809, el sentido de tal término no apunta precisamente a la idea de pil $i \zeta$.

70 Nietzsche (2003: 141).

71 Plutarco, De sollertia animalium 7.

* $\quad$ Es Doctor en Letras por la Universidad Nacional Autónoma de México, 1998-2003. Es Investigador adscrito al Centro de Estudios Clásicos (UNAM) y Profesor en el Colegio de Letras Clásicas de la Facultad de Filosofía y Letras. Fue Director de la revista Noua tellus (2006-2010; 2015-2017). Es miembro del proyecto internacional del Grup de recerca i acció teatral, Universitat de València (España) y del Proyecto de Excelencia "El coro trágico: su función y evolución en las tragedias griegas y latinas y su traducción en la dramaturgia occidental" de la misma Universidad. Fue Council Member de la International Society for the History of the Rhetoric (2011-2015). Algunas de sus publicaciones: Los retornos de Electra y de Orestes. Metamorfosis literaria de los personajes trágicos en la literatura hispanoamericana del siglo XX (2013); Esquilo, Prometeo encadenado. Introducción, traducción y notas (2013); Prometeo. El mito del héroe y del progreso. Estudio de literatura comparada (2006); editor de Lisias, Defensa ante Simón, introducción, traducción y notas de Paola Vianello Tessarotto (2015); coeditor de Retórica, argumentación y politica: lecturas e interpretaciones (2015). 